\title{
Application of protein chip combined with SELDI-TOF-MS detection to investigate serum protein expression in patients with silicosis fibrosis
}

\author{
GUITAO LIU ${ }^{1,2}$, JUNFENG YU $^{3}$, CUIDONG LI $^{2}$, XIAOYUN ZHOU ${ }^{2}$, LIPING NIE $^{2}$, \\ YANHUA WEI ${ }^{2}$, WENYU WANG ${ }^{1}$, YING ZHANG ${ }^{1}$, NUZIGULI NUSILAITI ${ }^{1}$, \\ PING HUA $^{1}$, XIAOHUA WANG ${ }^{2}$, WENLONG WEI ${ }^{2}$ and XINYAN LI ${ }^{4}$
}

\begin{abstract}
${ }^{1}$ Department of Occupational Disease Prevention and Control, The Fifth Affiliated Hospital of Xinjiang Medical University, Urumqi, Xinjiang 830011; ${ }^{2}$ Department of Respiratory Diseases, The Fifth Affiliated Clinical Medical College of Xinjiang Medical University, Xinjiang Medical University, Urumqi, Xinjiang 830054; ${ }^{3}$ Dermatological Department;

${ }^{4}$ Endocrinology Department, The Fifth Affiliated Hospital of Xinjiang Medical University,
\end{abstract} Urumqi, Xinjiang 830011, P.R. China

Received December 1, 2017; Accepted August 14, 2018

DOI: $10.3892 / \mathrm{etm} .2019 .7166$

\begin{abstract}
The present study aimed to observe the identification of biomarkers of silicosis based on the differentially expressed serum proteins between normal healthy individuals and patients with silicosis fibrosis. A total number of 20 patients with clinically diagnosed silicosis were screened, which were designated as the foundation treatment group. In addition, 20 age-matched healthy patients attending a check-up at the physical examination department were selected. Serum samples were obtained and a combined protein chip with surface-enhanced laser desorption ionization flight mass spectrometry was applied to perform serum analysis. Data preprocessing, screening differences in peak, hierarchical cluster analysis, Principal Component Analysis, construction of a decision tree model, and prediction based on the differences between peaks corresponding to proteins were performed to analyze the data. The results revealed differences in the proteins in serum between the normal group and the group prior to foundation treatment prediction. The corresponding names of the protein peak, predicted protein, and gene name were as follows: M1948_00, complement c3 frag, C3; M2017_02, amyloid- $\beta a 4$ protein, APP; and M2879_56, hepcidin, HAMP. Differentially expressed serum proteins in the normal group and the basis treatment group were predicted, including M2017_02, amyloid-ß344 protein, APP; M2879_56, hepcidin, HAMP; and M3224_97, fibrinogen- $\alpha$ chain frags, FGA. The
\end{abstract}

Correspondence to: Dr Xinyan Li, Endocrinology Department, The Fifth Affiliated Hospital of Xinjiang Medical University, 118 Henan Road, Urumqi, Xinjiang 830011, P.R. China E-mail: xinyanlii@126.com

Key words: silicosis fibrosis, surface-enhanced laser desorption ionization flight mass spectrometry, different protein in serum differentially expressed serum proteins in the group prior to basis treatment and the group following basis treatment were predicted, including M2001_69, amyloid- $\beta \mathrm{a} 4$ protein, APP; M2017_02, amyloid- $\beta a 4$ protein, APP, M4144_81, plasma protease $\mathrm{cl}$ inhibitor frag, and SERPING1. In conclusion, there were differences in the proteins in serum between the patients with silicosis fibrosis and healthy individuals.

\section{Introduction}

Pneumoconiosis follows the long-term inhalation of productive dust, which is the primary contributor to pulmonary fibrosis of systemic disease. It is also a progressive fibrotic lung disease, which is caused by occupational exposure to mineral dust and fibers (1). It is one of the most serious occupational disease hazards in China (2). Currently, occupational hazards exist in $>8,000$ enterprises in Xinjiang, China; $>1,300,00$ individuals may be contact with occupational hazards and there are $>16,000$ patients with various occupational diseases. All types of occupational disease hazard factors are increasing with the process of western development and, although there are certain protective measures, there are increasing numbers of patients with silicosis. According to incomplete current statistics, silicosis not only causes serious damage, due to silicon dust exposure, to the health of workers, but also severely reduces the labor force and quality of life, and causes economic loss to the country (3). According to statistics, the economic loss caused by occupational diseases each year is over 140 million RMB. Further investigations on diagnosis are required owing to new challenges in silicosis (4).

Surface-enhanced laser desorption ionization flight mass spectrometry (SELDI-TOF-MS) technology was used in the present study to detect the difference in serum protein between patients with silicosis fibrosis and normal healthy individuals, which is a novel effective method for the clinical diagnosis of silicosis by identifying markers for silicosis. 


\section{Materials and methods}

Serum sample information. A total of 60 male patients with silicosis were selected and, according to inclusion criteria and exclusion criteria, 20 patients with clinical cases of silicosis diagnosed within one period were screened and determined as the foundation treatment group, designated as group A. Therefore, of the 60 individuals in total recruited for the study in The Fifth Affiliated Hospital of Xinjiang Medical University (Urumqi, China), 20 patients with silicosis were included. In addition, 20 age-matched healthy patients attending check-ups at the physical examination department in the Fifth Affiliated Clinical Medical College of Xinjiang Medical University were selected as a normal healthy group, designated as group $\mathrm{C}$. The mean age of the three groups were $75.7 \pm 4.32$ years (group A), $76.1 \pm 5.62$ years (group B) and $74.8 \pm 4.31$ years (group C). All samples were collected between June 2014 and July 2015. Groups A and B were patients with silicosis, but the treatment options were different. The treatment of patients in Group A (basic treatment) was as follows: Oxygen therapy, coughing, and expectorant, anti-asthmatic and anti-inflammatory therapy. The treatment of patients in Group B was as follows: basic treatment $+2 \mathrm{ml}$ Deworming Vernonia Injection (repellent spotted chrysanthemum injection; Anhui Golden Sun Biochemical Pharmaceutical Co., Ltd., Fuyang, China) in $10 \mathrm{ml}$ of $0.9 \%$ physiological saline for nebulization. Venous blood $(5 \mathrm{ml})$ was centrifuged at $900 \mathrm{x} \mathrm{g}$ for $10 \mathrm{~min}$ at $4^{\circ} \mathrm{C}$; the serum was removed and stored in a freezer at $-80^{\circ} \mathrm{C}$. Fasting morning venous blood samples were obtained from the normal group (group C), the pre-foundation treatment group (A-Q) and the post-foundation treatment group $(\mathrm{A}-\mathrm{H})$. There were a total of 60 samples from the three groups, as each group had 20 biological repeats. SELDI-TOF-MS detection analysis was performed on the samples. The foundation treatment for silicosis comprised chemotherapy using poly 2-vinyl pyridine nitroxide (5). Patients with silicosis can be rapidly detected by detecting the plasma levels of tumor necrosis factor- $\alpha$ and matrix metalloproteinase 9 (6). The changes in the expression levels of numerous proteins following foundation treatment occur in the same patient and correlate with disease status. The inclusion criteria were as follows: History of dust exposure; early symptoms or signs; X-ray examination as the main basis for the diagnosis of silicosis; laboratory tests for the examination of early diagnostic indicators; pulmonary function tests showing pulmonary ventilation disorders. The exclusion criteria comprised patients who did not meet the inclusion criteria, did not attend follow-up or did not sign the informed consent forms.

Equipment and instrument. The Ciphergen ${ }^{\circledR}$ SELDI-TOF-MS mass spectrometer (protein fingerprint device) was used in the present study (Ciphergen Biosystems, Inc., Fremont, CA, USA). In order to identify the biomarkers, the Protein Chip SELDI system was used, which can rapidly produce a protein molecular weight map from a large number of complex biological samples. Using surface enhanced laser desorption ion technology, it is able to capture, detect and measure the molecular weight of peptides and proteins in complex biological samples (4).

SELDI protein chip. The covalent coupling of selected proteins or other target molecules can be implemented on the surface of a chip. A particular subgroup of complex protein samples can be captured by the chip through simple chemistry or protein interaction.

Following incubation, protein that was not combined with other ingredients from the chip surface was cleared. Only those specifically binding proteins were retained for further analysis. Following the elution step, the organic solution of energy absorption molecules was added. The chip in the SELDI reading machine was analyzed, which involved a type of time of flight mass spectrometry. Once in a gaseous state, charged protein molecules under the effect of a separation voltage show rapid movement, termed 'flight'. The separation voltage for all the molecules in the sample has the same effect, with differences in time of flight according to the different molecular weight. The SELDI reading machine recorded the time of flight, and converted this to a molecular weight.

Contrast strategy and analysis of the content. A total of three comparative analyses with the following comparisons, respectively, were performed, and data was obtained for further bioinformatics analysis: C, vs. A-Q; C, vs. A-H; and A-Q, vs. A-H. The data analysis process included data preprocessing, differences in peak screening, hierarchical cluster analysis, Principal Component Analysis (PCA), construction of a decision tree model, and protein prediction based on differences between the peak corresponding to proteins.

Statistical analysis. SPSS 17.0 software (SPSS, Inc., Chicago, IL, USA) was used for the quantitative data, with two sets of equal variances, using a Student's t-test. Two sets of heterogeneity of variance, with rank and inspection, disordered classification data were analyzed using the $\chi^{2}$ test. The Wilcoxon sum rank test was used with a capacity of $<10$. The specific steps of the test were as follows: Firstly, data of two samples were mixed and ranked from the smallest to the largest (the smallest data order is 1 and the largest data order is $n 1+n 2)$. Secondly, the ranks of data in the smaller capacity sample are add, that is, the rank sum, denoted by Ť. Thirdly, the $\mathrm{T}$ value was compared with the critical value at a certain level of significance in the rank sum test table. If $\mathrm{T} 1<\mathrm{T}<\mathrm{T} 2$, the difference between the two samples is insignificant; $\mathrm{T}<\mathrm{T} 1$ or $\mathrm{T} \geq \mathrm{T} 2$ indicates that the two samples are significantly different. The Wilcoxon rank sum test was used in the present study to obtain P-values. The difference in protein peaks was determined by calculating the P-value to determine the significance of differences of each protein peak. The permutation tests were performed with statistical tools in SIMCA 14.0 software (Umetrics AB, Umea, Sweden). $\mathrm{P}<0.05$ was considered to indicate a statistically significant difference.

\section{Results}

Data preprocessing. Raw data analyses were performed using Ciphergen Protein Chip software correction processing to obtain the peak data. A mass-to-charge ratio $<1,000$ of the peak was considered the substrate peak, and the subsequent data was filtered based on the peak.

Difference in peak filtering. The peak between two groups was compared using the Wilcoxon sum rank test, using the peak 
Table I. C, vs. A-Q group differences in peak filtering.

\begin{tabular}{|c|c|c|c|c|c|}
\hline SAMP_GRP & P-value & q-value & VIP & C average & A-Q average \\
\hline M1004_63 & $2.9018 \times 10^{-11}$ & $4.38 \times 10^{-9}$ & 2.8325 & 9.337262319 & 20.59812918 \\
\hline M1009_81 & $2.884 \times 10^{-6}$ & $1.4043 \times 10^{-5}$ & 1.18109 & 31.51986384 & 40.84034414 \\
\hline M1019_45 & $4.3527 \times 10^{-10}$ & $1.5438 \times 10^{-8}$ & 2.63561 & 4.718782081 & 12.56350599 \\
\hline M1031_99 & $6.529 \times 10^{-10}$ & $1.6425 \times 10^{-8}$ & 3.48656 & 7.811703062 & 21.54302217 \\
\hline M1083_37 & $4.9091 \times 10^{-6}$ & $2.0583 \times 10^{-5}$ & 1.12792 & 0.294565816 & 2.199163708 \\
\hline M1098_33 & $1.3412 \times 10^{-7}$ & $1.1292 \times 10^{-6}$ & 1.67063 & 0.38657576 & 3.615140978 \\
\hline M1101_43 & $9.9241 \times 10^{-9}$ & $1.07 \times 10^{-7}$ & 2.14677 & 0.927844358 & 5.631289799 \\
\hline M1103_90 & $2.0167 \times 10^{-9}$ & $3.3824 \times 10^{-8}$ & 1.64852 & 0.479273296 & 3.302777091 \\
\hline M1114_98 & $4.0713 \times 10^{-7}$ & $2.6719 \times 10^{-6}$ & 1.5397 & 0.418107229 & 3.207923021 \\
\hline M1123_40 & $3.028 \times 10^{-8}$ & $2.8566 \times 10^{-7}$ & 1.64771 & 0.54015768 & 3.571119791 \\
\hline M1127_55 & $1.3276 \times 10^{-8}$ & $1.3359 \times 10^{-7}$ & 1.91652 & 0.784175155 & 4.616498053 \\
\hline M1138_12 & $9.6475 \times 10^{-6}$ & $3.6341 \times 10^{-5}$ & 1.25759 & 0.461889022 & 2.446496536 \\
\hline M1144_16 & $2.0167 \times 10^{-9}$ & $3.3824 \times 10^{-8}$ & 2.7147 & 1.740541284 & 9.570840078 \\
\hline M1146_35 & $6.529 \times 10^{-10}$ & $1.6425 \times 10^{-8}$ & 2.77186 & 2.612216217 & 10.34906681 \\
\hline M1150_36 & $3.9464 \times 10^{-9}$ & $5.4153 \times 10^{-8}$ & 1.87836 & 1.903402107 & 6.508579836 \\
\hline M1163_78 & 0.00010426 & 0.00029951 & 1.28628 & 0.268622126 & 2.446015217 \\
\hline M1190_81 & $2.8978 \times 10^{-5}$ & $9.678 \times 10^{-5}$ & 1.21026 & 0.31970599 & 2.341884927 \\
\hline M1207_98 & $6.529 \times 10^{-10}$ & $1.6425 \times 10^{-8}$ & 2.49502 & 0.550691748 & 6.396113855 \\
\hline M1216_31 & $2.7567 \times 10^{-10}$ & $1.3978 \times 10^{-8}$ & 2.92377 & 2.903470782 & 11.45476404 \\
\hline M1230_37 & $4.9091 \times 10^{-6}$ & $2.0583 \times 10^{-5}$ & 1.5803 & 0.390190586 & 3.294667162 \\
\hline M1234_44 & $1.5646 \times 10^{-5}$ & $5.4923 \times 10^{-5}$ & 1.72882 & 1.132329262 & 5.002732013 \\
\hline M1259_38 & $4.0713 \times 10^{-7}$ & $2.6719 \times 10^{-6}$ & 1.72134 & 0.668984452 & 3.864822477 \\
\hline M1324_75 & $4.1219 \times 10^{-6}$ & $1.8269 \times 10^{-5}$ & 1.32713 & 0.326495903 & 2.353783547 \\
\hline M1351_32 & 0.00025797 & 0.0006279 & 1.07649 & 0.222331714 & 1.765712861 \\
\hline M1368_84 & $2.0167 \times 10^{-9}$ & $3.3824 \times 10^{-8}$ & 2.00209 & 0.614290076 & 4.832761142 \\
\hline M1435_91 & $2.4028 \times 10^{-6}$ & $1.2236 \times 10^{-5}$ & 1.64372 & 0.304051349 & 3.099785952 \\
\hline M1454_17 & $9.9241 \times 10^{-9}$ & $1.07 \times 10^{-7}$ & 2.09005 & 0.237729927 & 4.569096508 \\
\hline M1475_93 & 0.00015512 & 0.0004181 & 1.1731 & 0.172207775 & 2.014840182 \\
\hline M1505_23 & $4.5102 \times 10^{-5}$ & 0.00014227 & 1.27917 & 0.903329951 & 3.306640883 \\
\hline M1625_88 & $1.6891 \times 10^{-7}$ & $1.3726 \times 10^{-6}$ & 1.48823 & 0.535477091 & 3.408169271 \\
\hline M1700_90 & $2.1171 \times 10^{-7}$ & $1.6498 \times 10^{-6}$ & 1.37375 & 0.23234938 & 2.32507649 \\
\hline M1948_00 & 0.00015512 & 0.0004181 & 1.18882 & 0.126504245 & 1.85957764 \\
\hline M2017_02 & $2.8292 \times 10^{-9}$ & $4.2705 \times 10^{-8}$ & 2.28118 & 3.299510237 & 10.03986804 \\
\hline M2879_56 & 0.00022766 & 0.00057042 & 1.78224 & 6.897042594 & 14.34943243 \\
\hline M2959_08 & $7.5712 \times 10^{-7}$ & $4.5713 \times 10^{-6}$ & 2.03316 & 0.916531467 & 5.060081501 \\
\hline M3224_97 & 0.00093342 & 0.00185385 & 1.06247 & 2.49928245 & 1.090001717 \\
\hline M3246_10 & $2.4028 \times 10^{-6}$ & $1.2236 \times 10^{-5}$ & 1.87892 & 0.396642163 & 4.2861341 \\
\hline M3322_38 & 0.04595423 & 0.04441369 & 1.54968 & 7.748435198 & 4.898142987 \\
\hline M3825_21 & 0.00074741 & 0.00154007 & 1.08572 & 2.514007357 & 0.827869797 \\
\hline M3900_31 & 0.00022766 & 0.00057042 & 1.24374 & 2.663706342 & 0.890604754 \\
\hline M4421_61 & $5.2082 \times 10^{-5}$ & 0.00016044 & 1.69686 & 4.732555028 & 1.951991338 \\
\hline M4478_27 & $3.2864 \times 10^{-7}$ & $2.3028 \times 10^{-6}$ & 1.54532 & 2.864591283 & 0.276282046 \\
\hline M4715_56 & $3.8989 \times 10^{-5}$ & 0.00012563 & 1.51004 & 3.657925544 & 1.239881596 \\
\hline
\end{tabular}

C, normal group; A-Q, pre-foundation treatment group.

P-value to judge whether there were significant differences between the two groups. By selecting different peaks, differences between peaks were compared and the screening results for $\mathrm{C}$, vs. A-Q (Table I), C, vs. A-H (Table II), and A-Q, vs. S A-H (Table III) were obtained. As shown in Table I, the normal group and pre-foundation treatment group had statistically significant differences between peaks. As shown in Table II, the normal group and post-foundation treatment group had statistically significant differences between peaks. As shown in Table III, between the pre- and post-foundation 
Table II. C, vs. A-H group differences in peak filtering.

\begin{tabular}{|c|c|c|c|c|c|}
\hline SAMP_GRP & P-value & q-value & VIP & $\mathrm{C}$ average & A-H average \\
\hline M1004_63 & $1.06 \times 10^{-7}$ & $8.18 \times 10^{-6}$ & 2.75206 & 9.337262319 & 18.36057094 \\
\hline M1009_81 & $6.91 \times 10^{-5}$ & 0.000491 & 1.4842 & 31.51986384 & 40.48819307 \\
\hline M1019_45 & $3.45 \times 10^{-6}$ & $6.65 \times 10^{-5}$ & 1.97222 & 4.718782081 & 9.320910566 \\
\hline M1031_99 & $6.53 \times 10^{-8}$ & $8.18 \times 10^{-6}$ & 3.3601 & 7.811703062 & 18.49940089 \\
\hline M1083_37 & 0.00033 & 0.001496 & 1.01317 & 0.294565816 & 1.699066783 \\
\hline M1098_33 & 0.000595 & 0.002364 & 1.56859 & 0.38657576 & 2.544233659 \\
\hline M1101_43 & $6 \times 10^{-5}$ & 0.000455 & 2.06365 & 0.927844358 & 4.239463466 \\
\hline M1103_90 & $1.14 \times 10^{-5}$ & 0.000135 & 1.32065 & 0.479273296 & 2.349881329 \\
\hline M1114_98 & $6 \times 10^{-5}$ & 0.000455 & 1.58215 & 0.418107229 & 2.796677459 \\
\hline M1123_40 & 0.010314 & 0.020685 & 1.14424 & 0.54015768 & 2.276438971 \\
\hline M1127_55 & 0.001767 & 0.005778 & 1.68324 & 0.784175155 & 3.442394353 \\
\hline M1138_12 & 0.010314 & 0.020685 & 1.29039 & 0.461889022 & 2.551331219 \\
\hline M1144_16 & $9.1 \times 10^{-5}$ & 0.000562 & 2.53058 & 1.740541284 & 6.707315793 \\
\hline M1146_35 & 0.000258 & 0.001265 & 2.35356 & 2.612216217 & 7.147118481 \\
\hline M1150_36 & 0.000228 & 0.001156 & 1.31248 & 1.903402107 & 4.223835486 \\
\hline M1190_81 & 0.006145 & 0.015189 & 1.18846 & 0.31970599 & 1.670230569 \\
\hline M1207_98 & $6.91 \times 10^{-6}$ & $9.69 \times 10^{-5}$ & 1.95582 & 0.550691748 & 3.644110346 \\
\hline M1216_31 & $1.65 \times 10^{-6}$ & $4.25 \times 10^{-5}$ & 2.35906 & 2.903470782 & 8.011714226 \\
\hline M1225_21 & 0.008712 & 0.018838 & 1.15032 & 0.055092064 & 1.468164449 \\
\hline M1230_37 & $9.1 \times 10^{-5}$ & 0.000562 & 1.47151 & 0.390190586 & 2.300611105 \\
\hline M1234_44 & 0.000136 & 0.000774 & 1.93723 & 1.132329262 & 5.024199001 \\
\hline M1351_32 & 0.014297 & 0.025343 & 1.11582 & 0.222331714 & 1.538636715 \\
\hline M1368_84 & $3.36 \times 10^{-5}$ & 0.000317 & 1.76946 & 0.614290076 & 3.075023606 \\
\hline M1454_17 & $6.91 \times 10^{-5}$ & 0.000491 & 1.6592 & 0.237729927 & 2.389504296 \\
\hline M1625_88 & $2.88 \times 10^{-6}$ & $6.04 \times 10^{-5}$ & 1.7615 & 0.535477091 & 4.070970461 \\
\hline M2017_02 & 0.001291 & 0.004424 & 1.25703 & 3.299510237 & 6.380801455 \\
\hline M2879_56 & 0.002643 & 0.008118 & 1.43552 & 6.897042594 & 11.9477084 \\
\hline M2959_08 & 0.001435 & 0.004811 & 1.52917 & 0.916531467 & 2.90088487 \\
\hline M3224_97 & 0.035011 & 0.049694 & 1.06234 & 2.49928245 & 1.509255098 \\
\hline M3246_10 & $1.13 \times 10^{-6}$ & $3.47 \times 10^{-5}$ & 1.83767 & 0.396642163 & 3.275699253 \\
\hline M3322_38 & 0.004681 & 0.0126 & 1.88645 & 7.748435198 & 4.837010977 \\
\hline M3825_21 & 0.011207 & 0.021603 & 1.16951 & 2.514007357 & 1.159904936 \\
\hline M3900_31 & 0.011207 & 0.021603 & 1.09896 & 2.663706342 & 1.345515395 \\
\hline M4412_23 & 0.012166 & 0.022765 & 1.03269 & 2.483203325 & 1.25835564 \\
\hline M4421_61 & 0.003211 & 0.00949 & 1.89073 & 4.732555028 & 2.263517789 \\
\hline M4715_56 & $9.65 \times 10^{-6}$ & 0.000122 & 1.86603 & 3.657925544 & 0.858452439 \\
\hline M4770_22 & 0.009484 & 0.019762 & 1.05903 & 1.036151502 & 0.130670044 \\
\hline M4797_31 & 0.022719 & 0.03575 & 1.37116 & 4.054278147 & 1.971892733 \\
\hline M4825_09 & 0.014297 & 0.025343 & 1.30691 & 3.330875754 & 2.065185447 \\
\hline M4832_49 & 0.000372 & 0.00164 & 1.29409 & 2.046751735 & 0.412735635 \\
\hline M5254_17 & 0.000201 & 0.001052 & 1.5746 & 1.256545457 & 4.629496349 \\
\hline M5341_27 & $2.64 \times 10^{-7}$ & $1.36 \times 10^{-5}$ & 4.89611 & 9.675443865 & 26.47358094 \\
\hline M5775_96 & 0.037519 & 0.052238 & 1.1959 & 2.1058316 & 0.742538154 \\
\hline
\end{tabular}

C, normal group; A-H, post-foundation treatment group.

treatment group, there were statistically significant differences in peaks.

Hierarchical clustering analysis. The hierarchical cluster analysis was performed on the differences in peaks, with a clustering diagram showing the association between the samples. Each line represents a peak in the diagram (Fig. 1), and each column represents a sample. The red and green colors represent sample testing content is higher and lower, respectively. The comparison results for each group are shown 
Table III. A-Q, vs. A-H group differences in peak filtering.

\begin{tabular}{|c|c|c|c|c|c|}
\hline SAMP_GRP & P-value & q-value & VIP & A-Q average & A-H average \\
\hline M1004_63 & 0.039989 & 0.415819 & 1.16467 & 20.59813 & 18.36057 \\
\hline M1019_45 & 0.002325 & 0.220852 & 2.23625 & 12.56351 & 9.320911 \\
\hline M1123_40 & 0.044054 & 0.427081 & 1.27539 & 3.57112 & 2.276439 \\
\hline M1146_35 & 0.036234 & 0.403855 & 2.52543 & 10.34907 & 7.147118 \\
\hline M1150_36 & 0.000708 & 0.220852 & 1.73778 & 6.50858 & 4.223835 \\
\hline M1207_98 & 0.013617 & 0.299041 & 2.71017 & 6.396114 & 3.64411 \\
\hline M1216_31 & 0.00639 & 0.247157 & 2.00268 & 11.45476 & 8.011714 \\
\hline M1245_23 & 0.036234 & 0.403855 & 2.37039 & -0.30271 & 0.870859 \\
\hline M1259_38 & 0.048441 & 0.437643 & 1.91349 & 3.864822 & 2.087152 \\
\hline M1324_75 & 0.021484 & 0.333673 & 1.45305 & 2.353784 & 1.244105 \\
\hline M1368_84 & 0.044054 & 0.427081 & 2.00074 & 4.832761 & 3.075024 \\
\hline M1435_91 & 0.013617 & 0.299041 & 1.76205 & 3.099786 & 1.304288 \\
\hline M1475_93 & 0.048441 & 0.437643 & 1.73211 & 2.01484 & 0.937137 \\
\hline M1505_23 & 0.026642 & 0.363733 & 1.35806 & 3.306641 & 2.081841 \\
\hline M1661_24 & 0.019234 & 0.317797 & 2.17012 & 1.212314 & 0.238766 \\
\hline M1694_85 & 0.004221 & 0.220852 & 1.66347 & 1.245148 & 0.288131 \\
\hline M1700_90 & 0.019234 & 0.317797 & 2.19981 & 2.325076 & 1.021293 \\
\hline M2001_69 & 0.013617 & 0.299041 & 1.81131 & 2.097512 & 0.993857 \\
\hline M2017_02 & 0.002712 & 0.220852 & 2.50106 & 10.03987 & 6.380801 \\
\hline M4144_81 & 0.003654 & 0.220852 & 1.30244 & -0.13272 & 0.656736 \\
\hline M4478_27 & 0.003654 & 0.220852 & 2.15012 & 0.276282 & 2.172395 \\
\hline M4861_39 & 0.048441 & 0.437643 & 1.32359 & 0.092989 & 0.802765 \\
\hline M5642_48 & 0.007296 & 0.254484 & 1.30207 & 0.955681 & 0.245088 \\
\hline M7564_68 & 0.012079 & 0.291543 & 1.54656 & 0.551073 & 1.201719 \\
\hline
\end{tabular}

A-Q, pre-foundation treatment group; A-H, post-foundation treatment group.

in heat maps: C, vs. A-Q (Fig. 1A), C, vs. A-H (Fig. 1B), and A-Q, vs. A-H (Fig. 1C). Shown in Fig. 1A is the association between the normal group and pre-foundation treatment group of samples, with red indicating sample testing content was higher and green indicating the sample testing content was lower. In Fig. 1B, the association between the normal group and post-foundation treatment group of samples is shown. In Fig. 1C, the association between pre- and post-foundation treatment group samples is shown.

PCA analysis. Using SIMCA software (version 14), the PCA analysis results were obtained. The scoring results for the total and the comparisons in each group are shown. As shown in Fig. 2A, the normal group and pre-foundation treatment group were distinguished. As shown in Fig. 2B, the normal group and post-foundation treatment group were distinguished.

Orthogonal Projections to Latent Structures Discriminant Analysis (OPLS-DA) model construction. The C, vs. A-Q group OPLS-DA scoring chart is shown in Fig. 3A, the displacement test (permutation test) diagram is shown in Fig. 3B, and the OPLS-DA load diagram is shown in Fig. 3C. It was shown that there was a significant difference in the protein level between the normal group and pre-foundation treatment group. The
C, vs. A-H group OPLS-DA scoring diagram is shown in Fig. 4A, the displacement test (permutation test) diagram is shown in Fig. 4B, and the OPLS-DA load diagram is shown in Fig. 4C. The protein level was significantly different between the normal group and post-foundation treatment group. The A-Q, vs. A-H group OPLS-DA scoring chart is shown in Fig. 5A, the displacement test (permutation test) diagram is shown in Fig. 5B and the OPLS-DA load diagram is shown in Fig. 5C. A-Q and A-H were markedly different (Fig. 5A). The displacement test of the OPLS-DA model demonstrated that the intercept of Q2 was less than 0.05, therefore the models were robust (Fig. 5B). Each point represents a protein that was expressed higher in the sample compared with another (Fig. 5C). Proteins on the left side of the axis were highly expressed in the A-H group and proteins on the right side of the axis were highly expressed in the A-Q group. These results demonstrate that proteins level were markedly different between the normal group and the post-foundation treatment group.

Differential protein prediction. Using Swiss-Prot (2017-10 release; https://www.uniprot.org/uniprot/?query=*\&fil=orga nism $\% 3 \mathrm{~A} \% 22 \mathrm{Homo}+$ sapiens+\%28Human $\% 29+\% 5 \mathrm{~B} 9606 \%$ $5 \mathrm{D} \% 22+\mathrm{AND}+$ reviewed $\% 3$ Ayes) as the standard protein data in the database, self-owned coding texted software was used to compare this with the amino acid molecular weight of protein, 
A

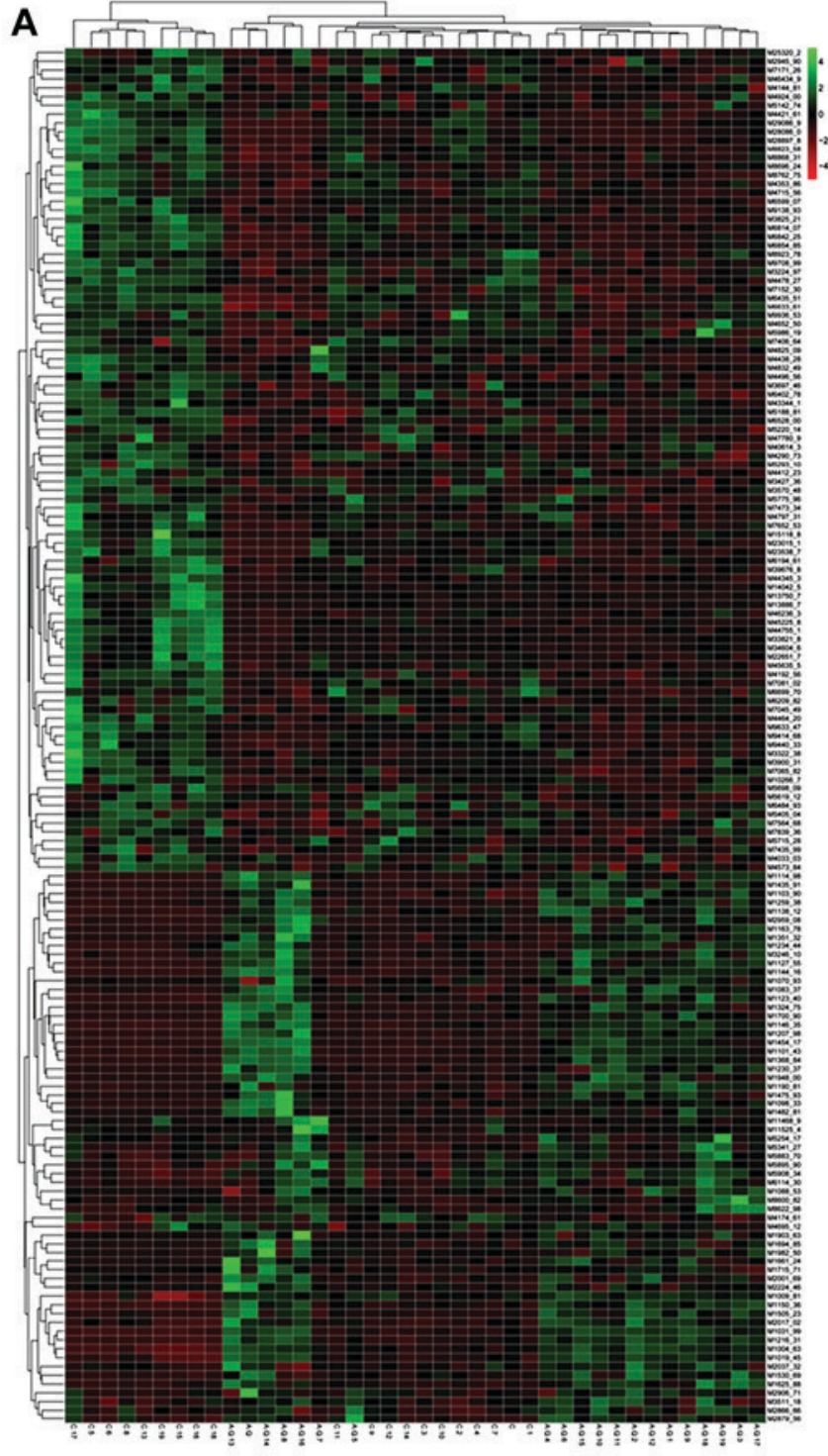

B

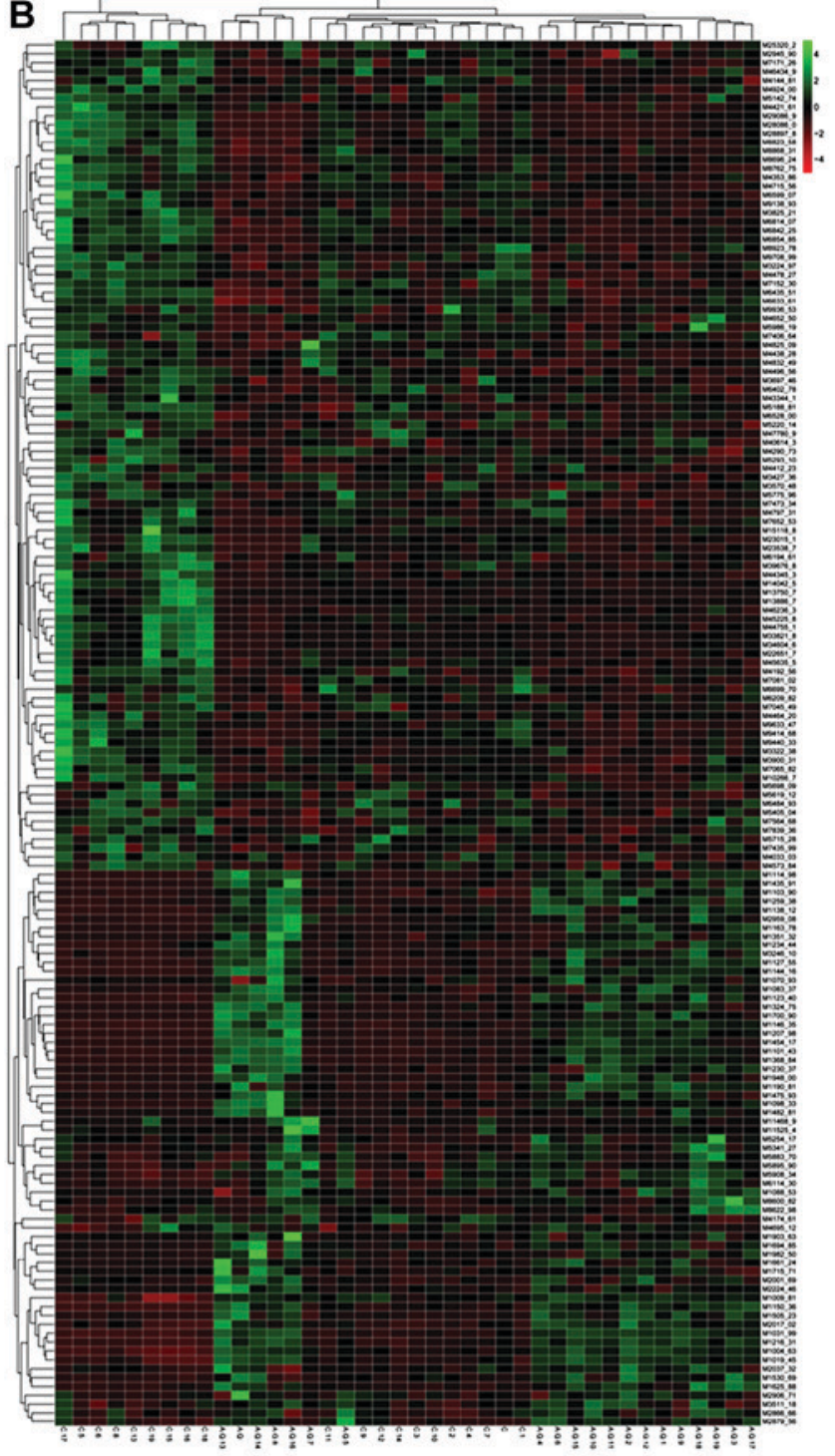

C

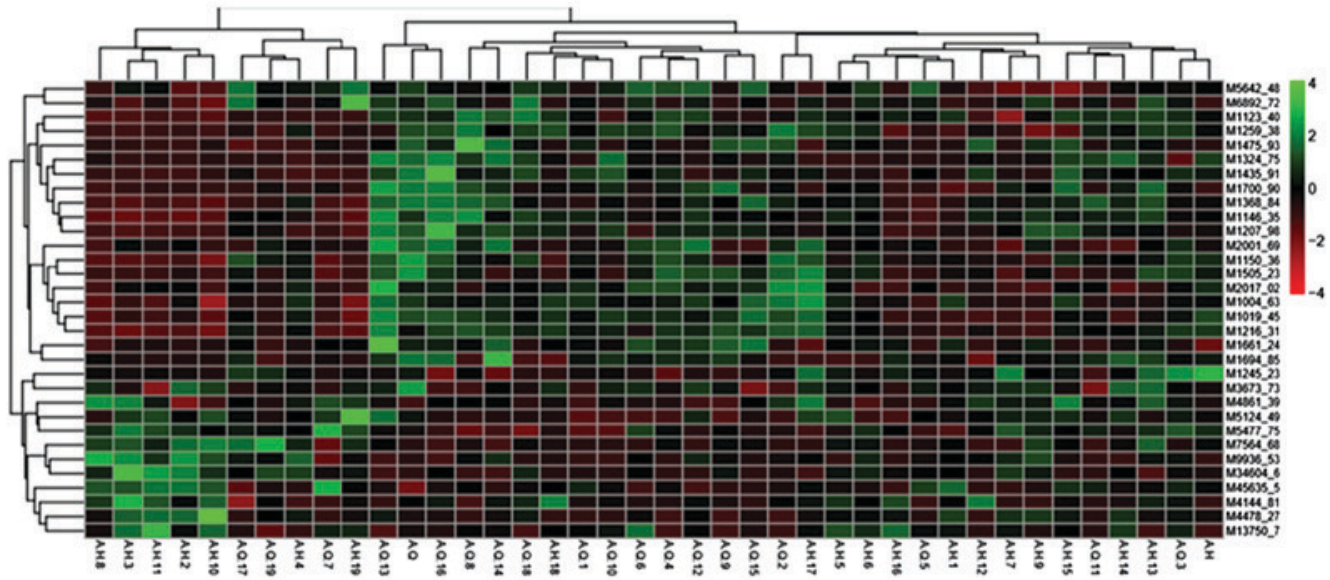

Figure 1. (A) C, vs. A-Q clustering results of peak differences; (B) C, vs. S A-H clustering results of peak differences. (C) A-Q, vs. A-H clustering results of peak differences. C, normal group; A-Q, pre-foundation treatment group; A-H, post-foundation treatment group. The red and green represented the level of protein expression. Relative quantitative protein expression results were normalized; the larger the value the darker the red and the smaller the value the darker the green.

and the most similar was found as the result of the prediction of the protein. The self-owned coding texted software performed peak-to-protein mapping using in-house MATLAB (version 7.5; The MathWorks, Inc., Natick, MA, USA) scripts. Briefly, the amino acid sequence for each protein in the human genome was obtained from UniProt Knowledge Base (KB)/Swiss-Prot (2017-10 release) (7). Potential amino acid sequence segmentation was identified in Empirical Proteomic Ontology-KB (7). 

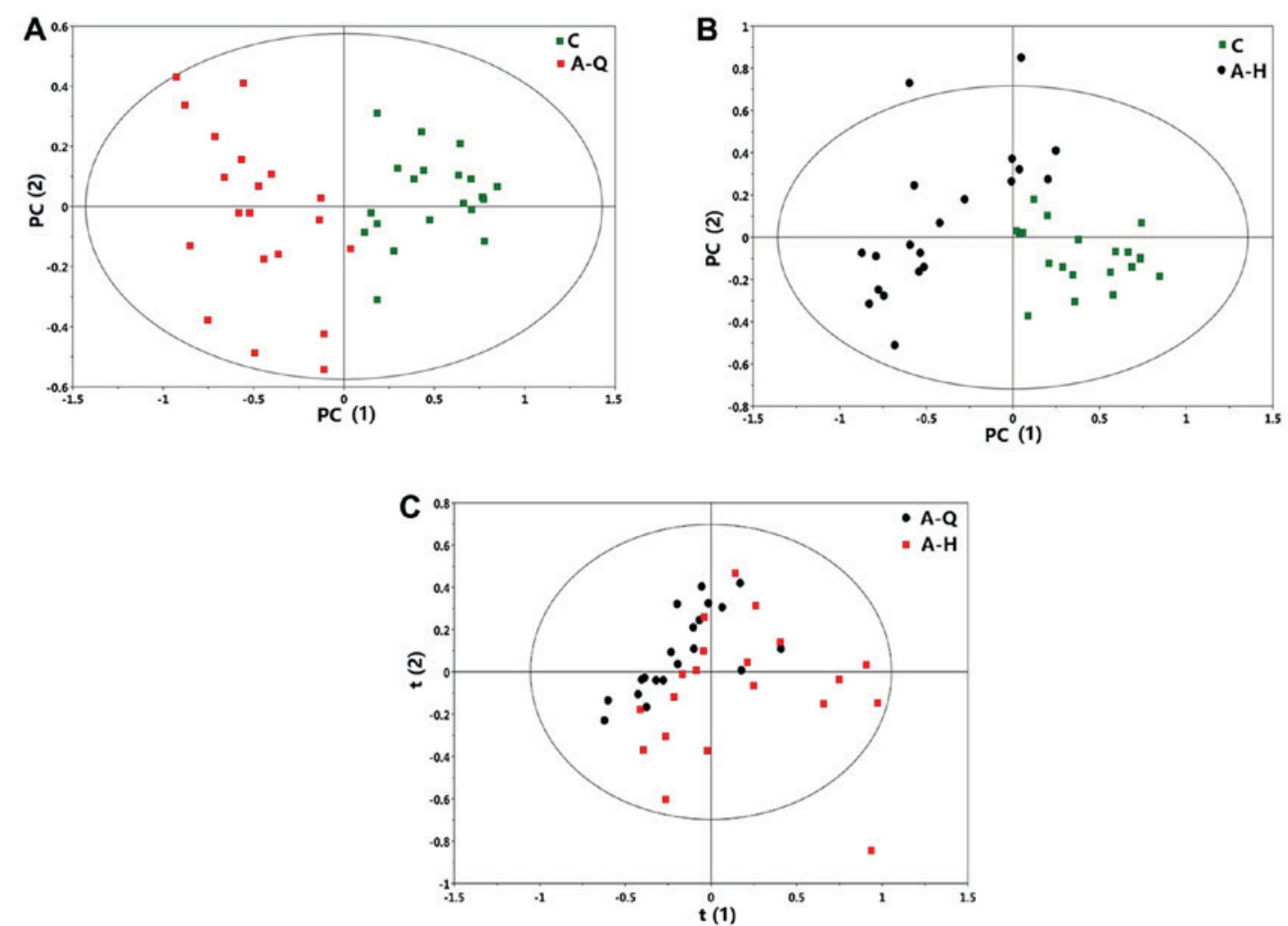

Figure 2. Comparison of score plots of PCA model obtained from C, A-Q and A-H groups. (A) C, vs. A-Q PCA scoring chart. (B) C, vs. A-H PCA scoring chart. (C) A-Q, vs. A-H PCA scoring chart. PCA, Principal Component Analysis; C, normal group; A-Q, pre-foundation treatment group; A-H, post-foundation treatment group.
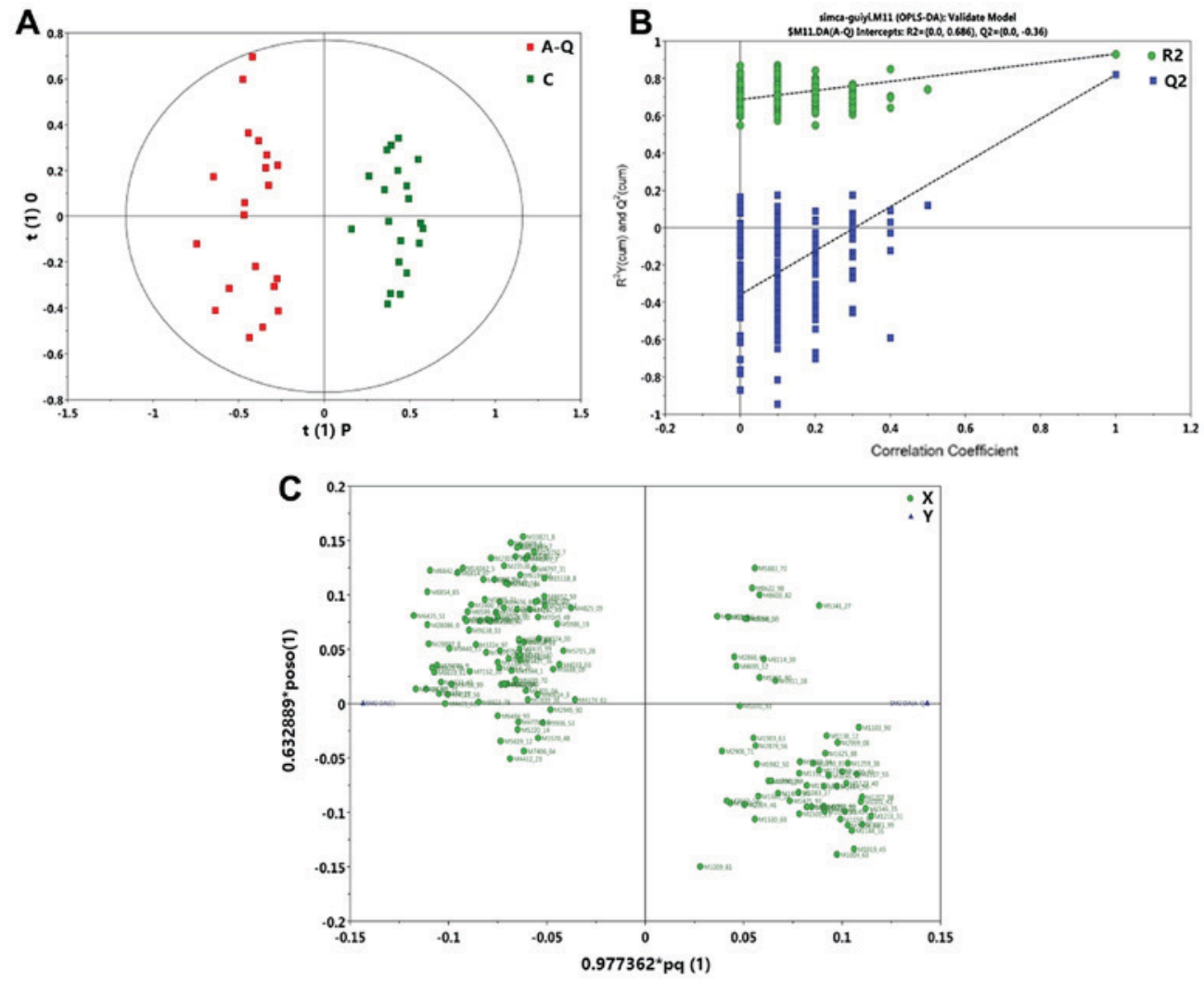

Figure 3. C, vs. A-Q group OPLS-DA model. (A) C, vs. A-Q group OPLS-DA scoring diagram shows the score plot of the OPLS-DA model obtained from the C and A-Q groups. (B) C, vs. A-Q group permutation test chart. A total of 200 permutations were performed, and the resulting R2 and Q2 values are plotted. Green circle, R2; blue square, Q2. The green line represents the regression line for R2 and the blue line for Q2. (C) C, vs. A-Q group OPLS-DA load diagram of the loading plot of the OPLS-DA model obtained from the C and A-Q groups. OPLS-DA, Orthogonal Projections to Latent Structures Discriminant Analysis; $\mathrm{C}$, normal group; A-Q, pre-foundation treatment group; A-H, post-foundation treatment group. 

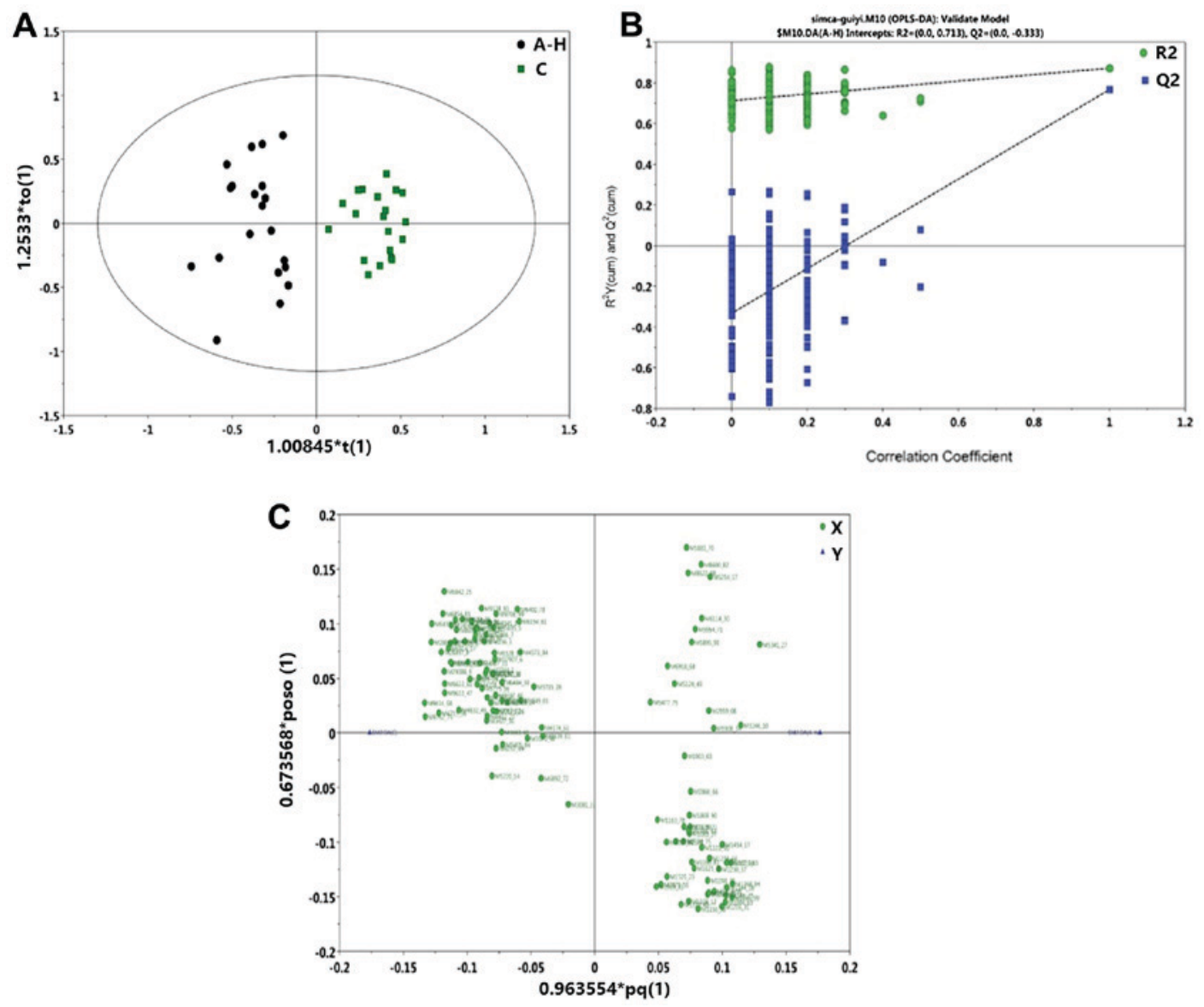

Figure 4. C, vs. A-H group OPLS-DA model. (A) C, vs. A-H group OPLS-DA scoring chart. (B) C, vs. A-H group displacement test chart. (C) C, vs. A-H group OPLS-DA load diagram. OPLS-DA, Orthogonal Projections to Latent Structures Discriminant Analysis; C, normal group; A-Q, pre-foundation treatment group; A-H, post-foundation treatment group.
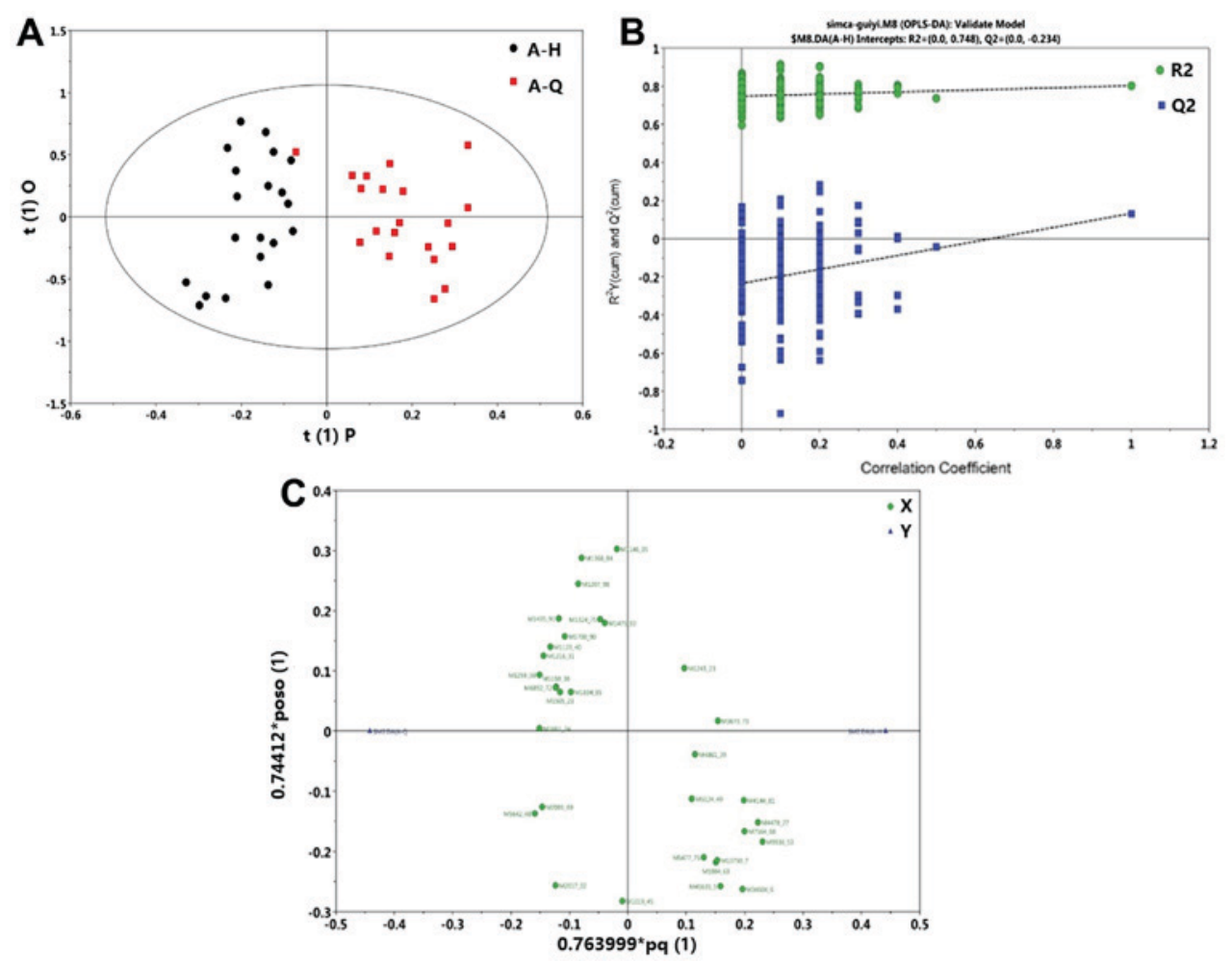

Figure 5. A-Q, vs. A-H group model. (A) A-Q, vs. A-H group OPLS-DA scoring chart. (B) A-Q, vs. A-H group permutation test chart. (C) A-Q, vs. A-H group OPLS-DA load diagram. OPLS-DA, Orthogonal Projections to Latent Structures Discriminant Analysis; C, normal group; A-Q, pre-foundation treatment group; A-H, post-foundation treatment group. 


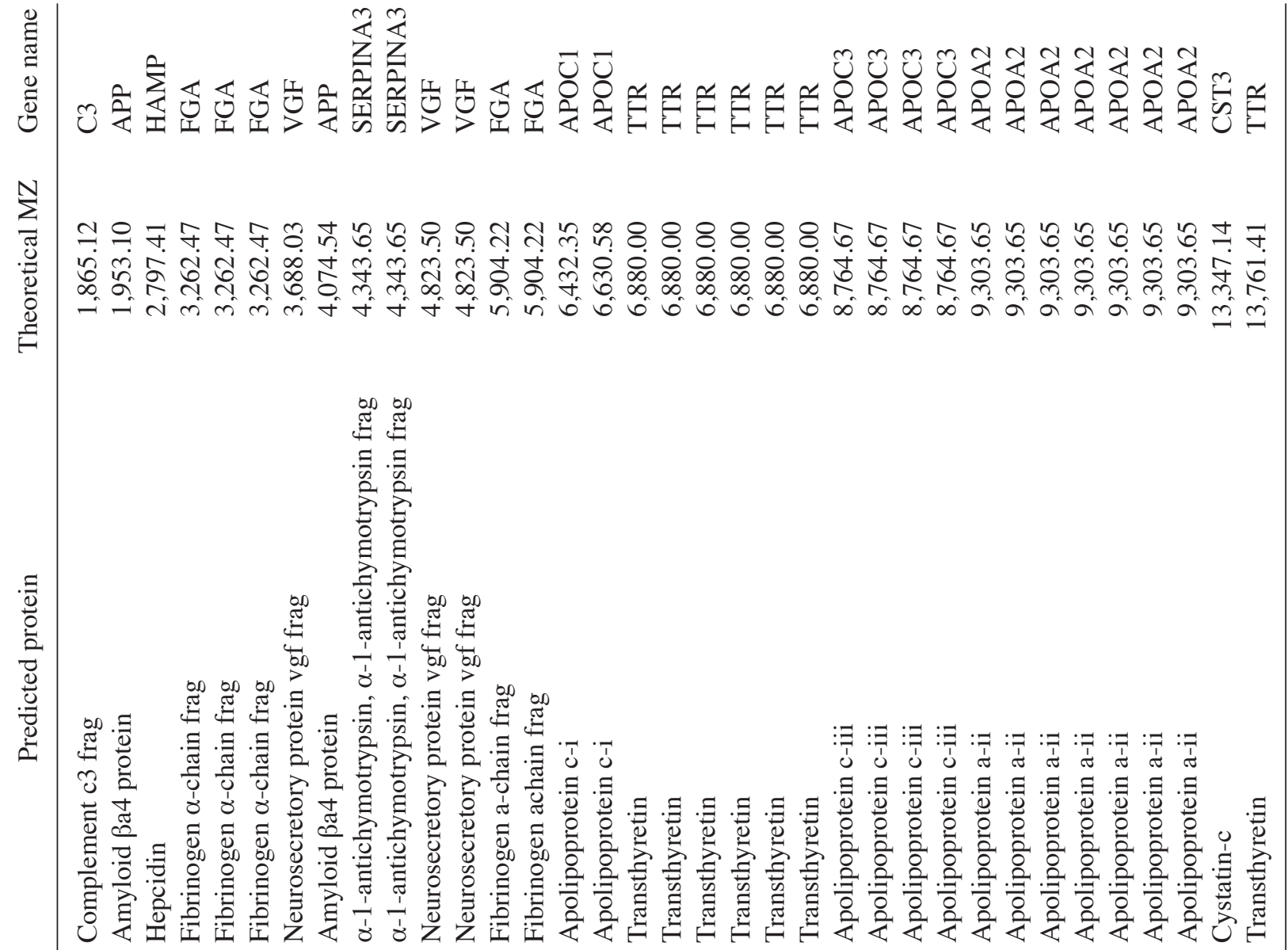

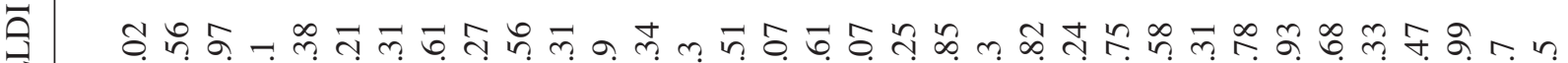

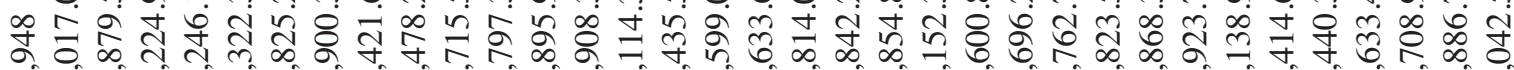

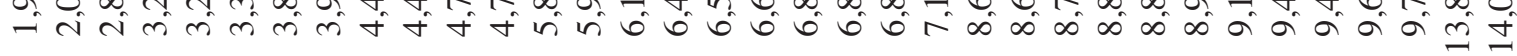

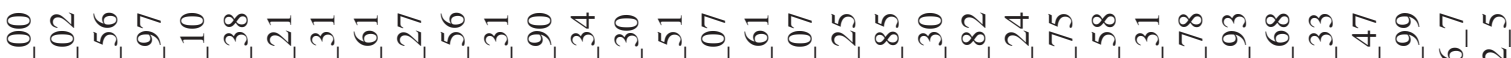
A

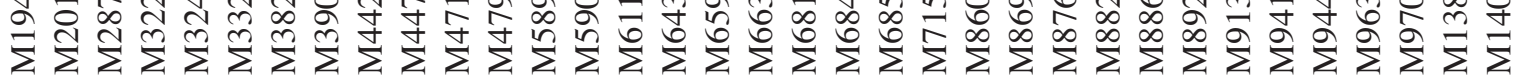

月

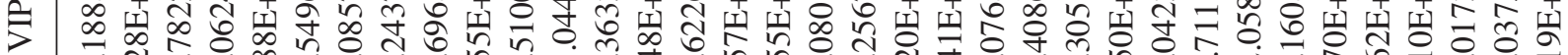
-

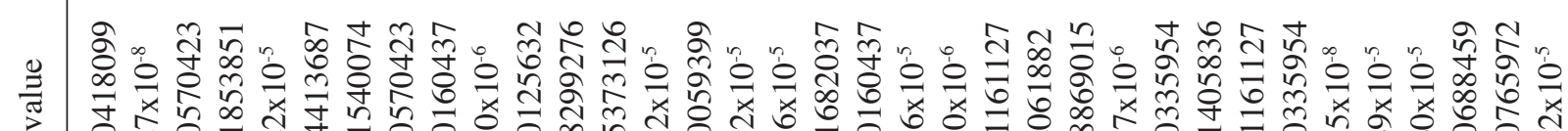
। \&

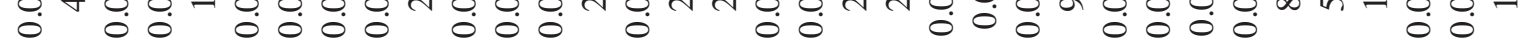
光。

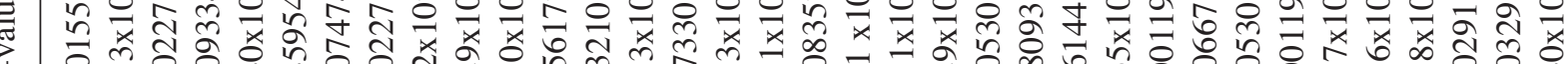

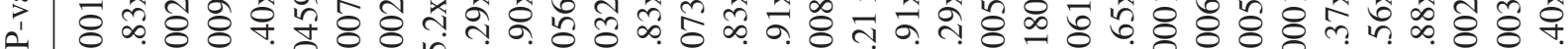
范

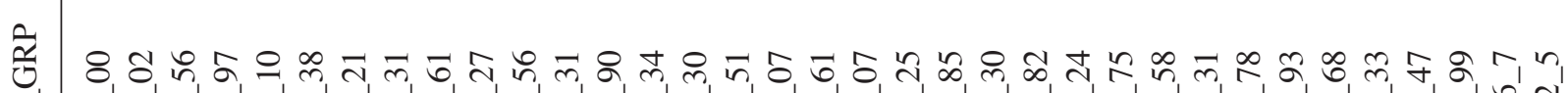




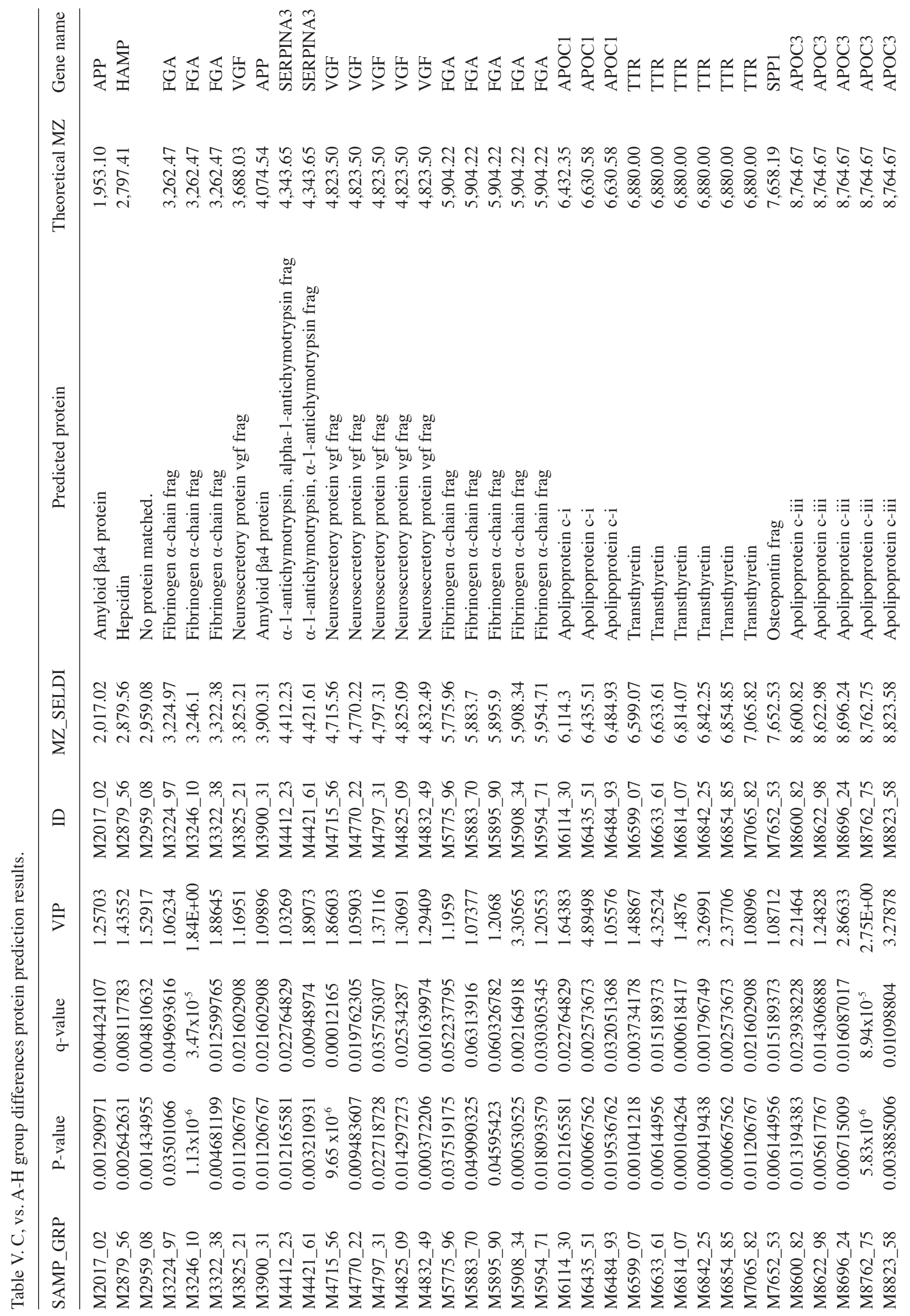




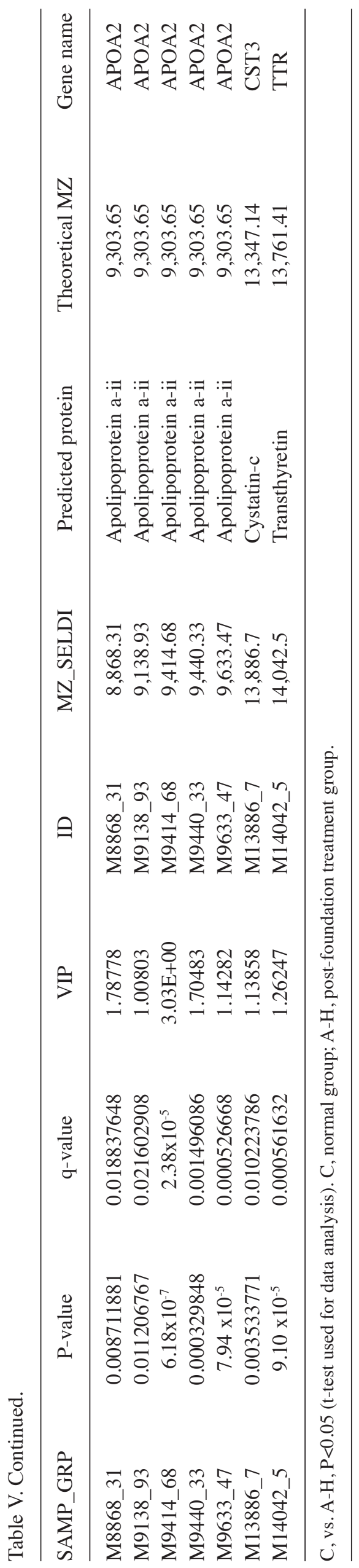

Peaks were mapped to the amino acid sequences based on the molecular weight; a 5\% deviation in molecular weight was allowed. Eventually, a list of mapped proteins was compiled into an Excel table. The differences in predicted proteins between C, vs. A-Q (Table IV), C, vs. A-H (Table V), and A-Q, vs. A-H (Table VI) were determined. From Table IV, it was possible to estimate the differences in serum protein between the normal group and pre-foundation treatment group of patients with silicosis. From Table V, differences in serum protein were estimated between the normal group and post-foundation treatment group of patients with silicosis. From Table VI, it was possible to estimate the differences in serum protein between the patients with silicosis pre-foundation treatment and post-foundation treatment, respectively. These results demonstrate that complement c3 frag, amyloid $\beta \mathrm{a} 4$ protein, hepcidin, fibrinogen $\alpha$-chain frags, plasma protease $\mathrm{cl}$ inhibitor frag and SERPING1 are markers for silicosis.

\section{Discussion}

According to previous studies, the pathological changes of silicosis are the main contributor to pulmonary fibrosis (7-11). The exact pathogenesis of silicosis remains to be fully elucidated, however, substantial evidence shows the involvement of alveolar macrophages, cytokines, Clara cells, oxidative stress, the immune system of the body, and $\mathrm{SiO}_{2}$ can lead to the occurrence and development of silicosis and be important in silicosis (12-17). The proteins that are differentially expressed in the serum of patients with silicosis are associated with silicosis $(18,19)$. There have been no studies reporting on a correlation between protein expression differences and silicosis-associated mortality.

SELDI-TOF-MS, through chemical or biological treatment on the surface of the protein chip, laser desorption ionization mass spectrometry equipment and artificial intelligence data analysis processing software comprised of three parts, is a type of ultramicro, high flux, fully automatic protein screening technology for blood serum, urine, cell extracts or other samples directly added for identification (20). The present study used SELDI-TOF-MS to obtain original data and perform detailed analysis; the main analytical steps included the following: Data pre-processing, differences in peak screening, hierarchical cluster analysis, PCA analysis, construction of a decision tree model, and prediction based on differences in peaks corresponding to proteins. The advantages of this method over current diagnostic methods are the accuracy, speed and low cost of the application clinically (21).

The small number of patients is a limitation of the present study, and further investigations are required to corroborate the preliminary results. In particular, for patients with similar infectious diseases, it is possible that similar diseases have a similar pattern of proteins, which should be included in future investigations. A study demonstrated that there is no correlation between protein expression differences and silicosis-associated mortality (22). From the above results, the group of patients with silicosis pre- and post-foundation treatment and the normal group showed differences in proteins in serum. Therefore, patients with silicosis fibrosis and normal healthy individuals have differences in serum protein expression; in order to further understand these proteins and improve a simple and feasible method for the diagnosis of patients with 
silicosis fibrosis, further investigations are to be performed for the identification of these differences in proteins. The aim of the present study was to offer occupational doctors a novel and alternative diagnostic test. The novel method, compared with present diagnostic strategies, of the proposed protein chip requires proper equipment, staff training and money. In conclusion, the present study identified complement $\mathrm{c} 3 \mathrm{frag}$, amyloid $\beta a 4$ protein, hepcidin, fibrinogen $\alpha$-chain frags, plasma protease c1 inhibitor frag and SERPING1 are markers for silicosis.

\section{Acknowledgements}

Not applicable.

\section{Funding}

The present study was supported by the National Natural Science Funds (grant no. 81360416).

\section{Availability of data and materials}

The datasets used and/or analysis in the present study are available from the corresponding author on reasonable request.

\section{Authors' contributions}

GL contributed to the conception and design of the study, literature research and analysis, and manuscript preparation and review. JU contributed to the design of the study. CL contributed to the experimental and clinical studies, data acquisition and analysis, statistical analysis, manuscript preparation and manuscript review. XZ contributed to the experimental studies and clinical studies, data acquisition and analysis, statistical analysis and manuscript preparation. LN contributed to the experimental and clinical studies and data acquisition. YW, WWa, XW and WWe contributed to the experimental studies. YZ, NN and PH contributed to the clinical studies. XL contributed to the conception of the study, literature research and manuscript editing and review, and is a guarantor of integrity of the entire study.

\section{Ethics approval and consent to participate}

This study is approved by the Ethics Committee in the Fifth Affiliated Clinical Medical College of Xinjiang Medical University. Signed informed consent was obtained from all patients.

\section{Patient consent for publication}

Not applicable.

\section{Competing interests}

The authors declare that they have no competing interests.

\section{References}

1. Jp NA, Imanaka M and Suganuma N: Japanese workplace health management in pneumoconiosis prevention. J Occup Health 59: 91-103, 2017. 
2. Liu H, Tang Z, Yang Y, Weng D, Sun G, Duan Z and Chen J: Identification and classification of high risk groups for coal workers' Pneumoconiosis using an artificial neural network based on occupational histories: A retrospective cohort study. BMC Public Health 9: 366, 2009.

3. Fichtner-Feigl S, Fuss IJ, Young CA, Watanabe T, Geissler EK, Schlitt HJ, Kitani A and Strober W: Induction of IL-13 triggers TGF-beta1-dependent tissue fibrosis in chronic 2,4,6-trinitrobenzene sulfonic acid colitis. J Immunol 178 : 5859-5870, 2007.

4. Mandal AK, Zhang Z, Ray R, Choi MS, Chowdhury B, Pattabiraman $\mathrm{N}$ and Mukherjee $\mathrm{AB}$ : Uteroglobin represses allergen-induced inflammatory response by blockingPGD2 receptor-mediated functions. J Exp Med 199: 1317-1330, 2004

5. Ernst H, Rittinghausen S, Bartsch W, Creutzenberg O, Dasenbrock C, Görlitz BD, Hecht M, Kairies U, Muhle H, Müller M, et al: Pulmonary inflammation in rats after intratracheal instillation of quartz, amorphous $\mathrm{SiO} 2$, carbon black, and coal dust and the influence of poly-2-vinylpyridine-N-oxide (PVNO). Exp Toxicol Pathol 54: 109-126, 2002.

6. Jiang PR, Cao Z, Qiu ZL, Pan JW, Zhang N and Wu YF: Plasma levels of TNF- $\alpha$ and MMP-9 in patients with silicosis. Eur Rev Med Pharmacol Sci 19: 1716-1720, 2015.

7. Lustgarten JL, Kimmel C, Ryberg H and Hogan W: EPO-KB: A searchable knowledge base of biomarker to protein links. Bioinformatics 24: 1418-1419, 2008.

8. Mahavadi P, Korfei M, Henneke I, Liebisch G, Schmitz G Gochuico BR, Markart P, Bellusci S, Seeger W, Ruppert C and Guenther A: Epithelial stress and apoptosis underlie Hermansky-Pudlak syndrome-associated interstitial pneumonia. Am J Respir Crit Care Med 182: 207-219, 2010.

9. Carneiro PJ, Clevelario AL, Padilha GA, Silva JD, Kitoko JZ, Olsen PC, Capelozzi VL, Rocco PR and Cruz FF: Cruz bosutinib therapy ameliorates lung inflammation and fibrosis in experimental silicosis. Front Physiol 8: 159, 2017.

10. Liu H, Cheng Y, Yang J, Wang W, Fang S, Zhang W, Han B, Zhou Z, Yao H, Chao J and Liao H: BBC3 in macrophages promoted pulmonary fibrosis development through inducing autophagy during silicosis. Cell Death Dis 8: e2657, 2017.

11. Chen Y, Li C, Lu Y, Zhuang H, Gu W, Liu B, Liu F, Sun J, Yan B, Weng D and Chen J: IL-10-Producing CD1d hi CD5+ regulatory B cells may play a critical role in modulating immune homeostasis in silicosis patients. Front Immunol 8: 110, 2017.

12. Bhattacharya S, Dey A, Pal A, Kar S and Saha S: Silicosis in the form of progressive massive fibrosis: A diagnostic challenge. Indian J Occup Environ Med 20: 114-117, 2016.
13. Rosengarten D, Fox BD, Fireman E, Blanc PD, Rusanov V, Fruchter O, Raviv Y, Shtraichman O, Saute M and Kramer MR: Survival following lung transplantation for artificial stone silicosis relative to idiopathic pulmonary fibrosis. Am J Ind Med 60: 248-254, 2017.

14. Mouratis MA and Aidinis V: Modeling pulmonary fibrosis with bleomycin. Curr Opin Pulm Med 17: 355-361, 2011.

15. Chiba Y, Kurotani R, Kusakabe T, Miura T, Link BW, Misawa M and Kimura S: Uteroglobin-related protein 1 expression suppresses allergic airway inflammation in mice. Am J Respir Crit Care Med 173: 958-964, 2006.

16. Liu P, Wang SX, Chen L, Wei MT, Liang XC, Wang YF and Tu ZG: Changes of Clara cell protein and surfactant protein-D in serum of patients with silicosis. Zhonghua Lao Dong Wei Sheng Zhi Ye Bing Za Zhi 25: 18-21, 2007 (In Chinese).

17. Anlar HG, Bacanli M, İritas S, Bal C, Kurt T, Tutkun E, Hinc Yilmaz O and Basaran N: Effects of occupational silica exposure on OXIDATIVE stress and immune system parameters in ceramic workers in TURKEY. J Toxicol Environ Health A 80: 688-696, 2017.

18. Zhu Z, Yang G, Wang Y, Yang J, Gao A, Niu P and Tian L: Suppression of thioredoxin system contributes to silica-induced oxidative stress and pulmonary fibrogenesis in rats. Toxicol Lett 222: 289-294, 2013

19. Liu H, Fang S, Wang W, Cheng Y, Zhang Y, Liao H, Yao H and Chao J: Macrophage-derived MCPIP1 mediates silica-induced pulmonary fibrosis via autophagy. Part Fibre Toxicol 13: 55, 2016.

20. Fang SC, Zhang HT, Wang CY and Zhang YM: Serum CA125 and NSE: Biomarkers of disease severity in patients with silicosis. Clin Chim Acta 433: 123-127, 2014

21. Lü GC, Yao JM and Zhang JW: Significance of detection of serum oxidant function in patients with silicosis. Zhonghua Lao Dong Wei Sheng Zhi Ye Bing Za Zhi 28: 52-53, 2010 (In Chinese).

22. Idec-Sadkowska I, Andrzejak R, Antonowicz-Juchniewicz J and Kaczmarek-Wdowiak B: Trials of casual treatment of silicosis. Med Pr 57: 271-280, 2006 (In Polish).

(c) (i) (9) This work is licensed under a Creative Commons cc) International (CC BY-NC-ND 4.0) License. 